\title{
Older adults who reported strain when caring for a spouse with disabilities had increased mortality
}

Schulz R, Beach SR. Caregiving as a risk factor for mortality. The Caregiver Health Effects Study.JAMA 1999 Dec

15;282:2215-9.

\section{QUESTION: Do older adults who care for a spouse with disabilities have an increased risk for mortality?}

Design

Cohort study with mean follow up of 4.5 years (Caregiver Health Effects Study, part of the Cardiovascular Health Study).

\section{Setting}

4 communities in the US.

\section{Participants}

819 older adults (mean age 80 y, age range $66-96$ y, $51 \%$ women, $90 \%$ white) who were living with their spouses. 392 were caregivers of a spouse who had difficulties with $\geq 1$ activity of daily living or instrumental activity of daily living because of physical or health problems or problems with confusion. 427 were non-caregivers (their spouses did not have these difficulties). Participants were drawn from a larger cohort study with inclusion criteria of $\geq 65$ years of age and plans to live in the study area for 3 years. Exclusion criteria were being wheelchair bound in the home, being unable to attend evaluations, or treatment for cancer. Follow up for mortality was $100 \%$.

\section{Assessment of risk factors}

Baseline data were collected on sociodemographic factors (age, sex, race, education, and stressful life events), cardiovascular health status (prevalent disease, subclinical disease, or no disease), and caregiving status (spouse not disabled [referent group], not helping disabled spouse, helping disabled spouse with no self reported emotional or physical strain, and helping disabled spouse with strain).

Source of funding: in part, National Institutes of Health.

For correspondence: Dr R Schulz,

Department of

Psychiatry and

University Center for

Social \& Urban

Research, University of

Pittsburgh, 121

University Place,

Pittsburgh, PA 15260 ,

USA. Fax +1 412624

4810.

Abstract and

commentary also

appear in

Evidence-Based Mental

Health.

A modified version of

the abstract also

appears in

Evidence-Based

Nursing.

\section{Main outcome measure}

All cause mortality.

\section{Main results}

During follow up, 103 participants died (16\% in the groups with a disabled spouse and $9 \%$ in the group whose spouses were not disabled). After adjustment for

Baseline caregiving status, sociodemographic factors, and cardiovascular health status associated with all cause mortality in older adults who were living with a disabled spouse

\begin{tabular}{ll} 
Baseline variable & $\begin{array}{l}\text { Relative risk } \\
\text { adjusted for baseline } \\
\text { factors ( } 95 \% \text { Cl) }\end{array}$ \\
\hline Helping spouse and caregiving strain & $1.63(1.00$ to 2.65$)$ \\
\hline Helping spouse but no reported strain & $1.08(0.61 \text { to } 1.90)^{\star}$ \\
\hline Not helping disabled spouse & $1.37(0.73 \text { to } 2.58)^{\star}$ \\
\hline Age (per year) & $1.10(1.06$ to 1.14$)$ \\
\hline Sex (men $v$ women) & $1.88(1.23$ to 2.88$)$ \\
\hline Race (black $v$ white) & $2.00(1.03$ to 3.89$)$ \\
\hline Prevalent disease at baseline & $3.30(1.79$ to 6.08$)$ \\
\hline${ }^{*}$ Not significant. &
\end{tabular}

sociodemographic factors and cardiovascular health status, caregivers who reported strain had a higher rate of all cause mortality than did people living with a nondisabled spouse; the other 2 groups (caregiving without strain or living with a disabled spouse but not providing care) did not have higher mortality. Age, sex, race, and prevalent disease were associated with increased risk for all cause mortality (table).

\section{Conclusion}

Older adults who provided care for a disabled spouse had an increased risk for all cause mortality if the caregiving was associated with physical or emotional strain.

\section{COMMENTARY}

Caregiving has long been associated with psychological and physical morbidity, but the study by Schulz and Beach is the first to identify a link between caregiving and mortality. The authors studied older adults living with their spouses, and the definition of caregiving hinged on the disability of the spouse rather than on the provision of help by the participant.

In an accompanying editorial, Kiecolt-Glaser and Glaser point out the potential for underestimation of mortality risk because of the broad definition used for caregiving and because caregiving status was identified only at baseline. They also highlight the complex interplay between physical health and depression and the particular disadvantages faced by caregiving spouses who have to cope simultaneously with an ill person in the house, the loss of a partner's support, and a reduction in opportunity to seek support elsewhere.

No details are given of spouses' illnesses, and participants' perception of who cares for whom seems based on comparison of their own and their spouses' illness to determine who is "less ill" or "more able." We may assume that caregivers with cardiovascular disease who rate themselves as "helping" are likely to have spouses with profound disabilities or terminal illness.

The need to focus care planning on the couple is emphasised in both the article and the editorial. To do this, the interaction between both partners must be considered rather than the simple summation of individual needs. Health and social care providers may need to instigate changes in conceptual frameworks used for assessment and intervention. For example, they may need to consider interpersonal or systemic models and changes in organisational procedures, such as cross referencing of records, before couple focused planning can be successful. Georgina Charlesworth, MPhil, ClinPsyD University of East Anglia Norwich, Norfolk, UK

1 Kiecolt-Glaser JK, Glaser R. Chronic stress and mortality among adults (Editorial). JAMA 1999;282:2259-60. 